\title{
Fault detection and location of power transmission lines using intelligent distance relay
}

\author{
Sa'ad Ahmed S. Al Kazzaz', Ibrahim Ismael' ${ }^{2}$, Karam Kairullah Mohammed ${ }^{3}$ \\ ${ }^{1}$ Department of Mechatronics Engineering, Mosul University, Iraq \\ ${ }^{2}$ Department of Electrical Engineering, Mosul University, Iraq \\ ${ }^{3}$ Department of Electrical Engineering, Universiti Teknologi Malaysia, Malaysia
}

\begin{tabular}{|c|c|}
\hline Article Info & ABSTRACT \\
\hline Article history: & \multirow{9}{*}{$\begin{array}{l}\text { The aim of this paper is to design a three-phase distance relay using an } \\
\text { adaptive neuro-fuzzy inference system algorithm (ANFIS). The proposed } \\
\text { relay is used to protect the power transmission lines where they are subjected } \\
\text { to faults continuously. These faults may produce a high electric current } \\
\text { which leads to high damage in power system equipment. The relay is used to } \\
\text { detect the transmission line faults by measuring the voltage and current } \\
\text { values for each phase. The line impedance is then calculated to detect the } \\
\text { faults and issue instantaneous trip signal to circuit breaker, to separate the } \\
\text { fault zone of the transmission line without affecting the work of other relays. } \\
\text { To isolate the faulty line without affecting the other lines within the network } \\
\text { the relays were trained using adaptive neuro-fuzzy inference system } \\
\text { (ANFIS). The obtained results through this work show that the designated } \\
\text { distance relay with (ANFIS) algorithm has the ability to detect the faults } \\
\text { occurrence, recognize it from the cases of the disturbance and to isolate only } \\
\text { the fault zone without affecting the work of other relays in system. }\end{array}$} \\
\hline Received May 27, 2019 & \\
\hline Revised Oct 22, 2019 & \\
\hline Accepted Dec 1, 2019 & \\
\hline Keywords: & \\
\hline ANFIS & \\
\hline Distance relay & \\
\hline Intelligent protection & \\
\hline Power system & \\
\hline
\end{tabular}

This is an open access article under the CC BY-SA license.

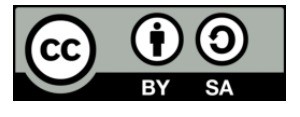

Corresponding Author:

Saad Ahmed Al Kazzaz

Department of Mechatronics Engineering

University of Mosul

College of Engineering, Mosul University Post Office, Mosul, Iraq.

Email: kazzazs60@uomosul.edu.iq

\section{INTRODUCTION}

The main part of the power system is the overhead transmission lines. The possibility of faults occurrence in the transmission line is greater than alternative real power structure parts where it is exposed to the surrounding natural environment [1]. Abnormal conditions can cause a short circuit faults which can be either single phase to ground, phase to phase or three phases. Most of the faults in the power system occur with the overhead lines are due to high transient voltage which introduce lightning and falling trees [2]. Many researchers from different organization are engaged in developing inteligint protection system for high voltage power transmission lines using distance relay [3-6]. Most of the researcher in their studies consider a star connected grid ignoring the fault effect in power line on the other grid components [3-7].

In a real grid especially the ring system, any relay trip at any line affect the other lines and relays in the system which may lead to shut down the whole system. In addition, unbalance condition, high load transit and disturbance with and without faults are the actual operating condition of the grid, hence need to be present in any design study of the distance relay [8,9]. It is important to find, distinguish, separate the fault zone and afterward return-back the power system to the working 
condition at the earliest opportunity. Furthermore, the time needed to ascertain the fault area lengthwise on the line of transmission affects the feature of the power system. Consequently, the impedance per kilometer of transmission line is genuinely steady; the relays react to the fault distance on the transmission line [10].

In this investigation, the well-designed intelligent relay is capable dealing with above mentioned circumstances where only line under fault condition is isolated. The implementation of the ANFIS for the modulation of the separation relay station transmission line protection is carried out. The recommended separation hand-off calculation is for the purpose of identifying the fault event. In addition to the segregation of the faulty transmission lines region that will not affect the work of the other lines. The proposed power system is based on the IEEE 9-bus which comprises twelve buses, three synchronous machines, six transmission lines, six transformers, three constant impedance loads and distance relays protecting transmission is implmented using MATLAB /Simulink program.

Distance relay, several protection relay systems were utilized to ensure transmission lines by voltage of $132 \mathrm{kv}$ or greater. The separation transfers possess quite a perfect position that provides vital backup for the transmission line. The protection is depending on voltage and current values which are relay station posited, for processing the resistance value of the verified line $[11,12]$. The ascertained resistance or known as impedance that was determined is differentiated and the impedance point achieved. On the occasion that the reach point impedance is not entirely reached by the deliberate impedance, there exists a recognition of the presence of a fault suspended betwixt the relay and the point of achieve. A distance relay evaluates the impedance to the fault point for the purpose of securing the line against short circuit faults [13, 14]. With the aims that the insurance zones are facilitated to the separation transfer through the utilization of the first zone, the second protection zone and the third zone, which is illustrated in Figure 1. There is a remote possibility that the third zone is needed to the successful gradation and working period of individual zones:

1 - The encapsulate of the first zone entails the main aim of $80 \%$ of section length.

2 - The second zone, covers nearly $120 \%$ of section length.

3 - The encapsulation of the second zone involves the main aim of $120 \%$ of the section length.

4- The third zone covers almost $200 \%$ of the length of the section.

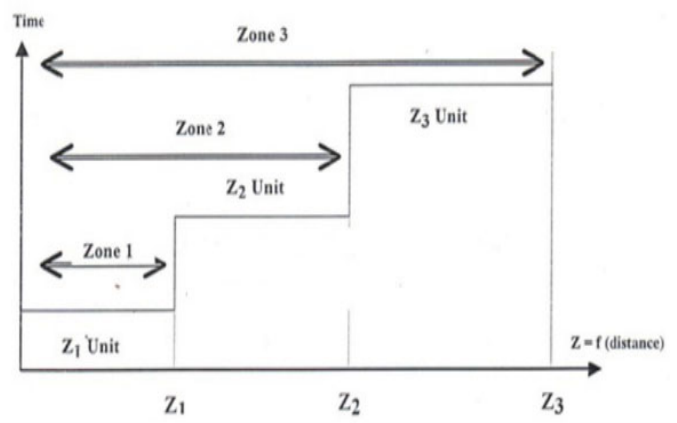

Figure 1. The distance drawing for protections zones for distance relays

\section{ZONE TIMER AND EVOLVING FAULTS}

Numerous researchers are viewed as the zone time postponement of the developing issue at the separation transfer structure. At the point when the transfers work with the diverse rationalities to secure a similar power arrange, a non-particular postponing process happens is conceivable [11, 15]. The standards has made it compulsory for the inventors to refer to planning and zone clocks values in mitigating the faults, by taking into account the zone timers behavior during the advancement of an individual distance zone protection to other distance protection zone, for example from the phase to earthing line towards other kind of fault such as in the three-phase system within an equal relay protection zone. Normally, customary protection is intended for relays dependent on conventional hand-off settings. Hence, the exactness of the compass of the relay transfer perhaps influenced by the distinctive blame conditions notwithstanding the system setup changes. Likewise, these plans are deterministic count accepting that the system is demonstrated on customary numerical devices. The portrayal of this system isn't viewed as fitting with not well characterized frameworks. [3, 16, 17]. 


\section{ADAPTIVE NEURO-FUZZY INFERENCE SYSTEM ALGORITHM (ANFIS).}

The fuzzy controller is used successfully in intelligent distance relay. There are many difficulties in fuzzy rules formation and in designing the membership functions that meet the system requirements. In other hand, artificial neural networks are a powerful tool used for complex system with different arbutuses. The combination of these methods has presented ANFIS, that gather fuzzy logics and neural networks advantages [18-20].

The fuzzy rules and membership functions generation of the fuzzy controller that approve the required specification and reduce the design time are implemented through neural networks learning. The system response is highly affected by the membership functions and the overlapping points. Tradition method for achieving the membership functions uses a trial and error. Fuzzy logic and neural networks have the ability for estimating and processing the data [21].

\section{THE FRAMEWORK ADAPTIVE NEURAL FUZZY NETWORK}

In The fluffy inference strategy of the type (Takagi-Sugeno) was implemented within the scheme. The yield of individual rule may be a straight and direct component for the interchanges of data, apart from the possession a stable value, or being a non-fluctuating value. The final yield results in a weighted average as per the yield of individual rule, where it is assumed that there exist a pair of units for the organization of ANFIS, which are the ' $\mathrm{R}$ ' and ' $\mathrm{S}$ ', and an individual yield of ' $\mathrm{O}$ ', as illustrated in Figure 2, comprise 2 rules as can be observed $[18,22]$ :

First Principle: In the event that $\mathrm{R}$ is equated to $\mathrm{X} 1$ and $\mathrm{S}$ is equated to $\mathrm{Y} 1$

Rule1: If $\mathrm{R}$ is $\mathrm{X} 1$ and $\mathrm{S}$ is $\mathrm{Y} 1$ then $\mathrm{fl}=\mathrm{e} 1 \mathrm{R}+\mathrm{t} 1 \mathrm{~S}+\mathrm{k} 1$

Second Principle: In the event that $\mathrm{R}$ is equated to $\mathrm{X} 2$ and $\mathrm{S}$ is equated to $\mathrm{Y} 2$ then

Rule2: If $\mathrm{R}$ is $\mathrm{X} 2$ and $\mathrm{S}$ is $\mathrm{Y} 2$ then $\mathrm{f} 2=\mathrm{e} 2 \mathrm{R}+\mathrm{t} 2 \mathrm{~S}+\mathrm{K} 2$

Figure 2, show the system of ANFIS where the fuzzy inference engine composite of five layers. The description of each layer is given below:

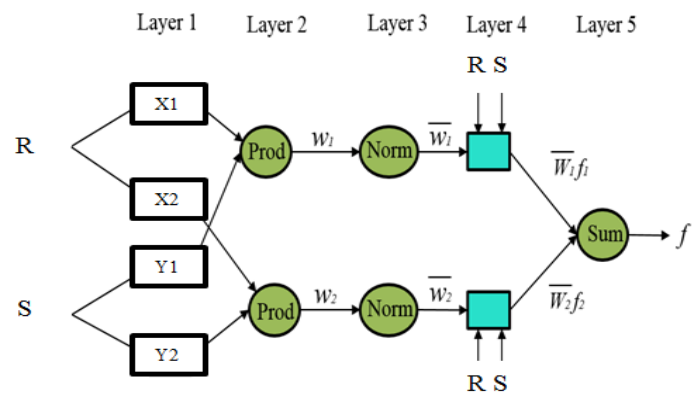

Figure 2. Installation of ANFIS

The first layer designates the type of the inputs membership functions (MF), that is; Node (k) entails a node operability comprising an adaptive node. The training progress of the said node alters the constituent of the node, that is transformed in obtaining a reduction of probable mistakes in the outcome, thus:

$$
\begin{aligned}
& u_{1, k}=\mu_{x k}(x) \text { for } k=1,2 \\
& u_{1, k}=\mu_{Y k-2}(y) \text { for } k=3,4
\end{aligned}
$$

Regard $\mu_{\mathrm{xk}}$ and $\mu_{\mathrm{Yk}-2}$ as grades connecting the input (MF), value $\mathrm{R}$ and value $\mathrm{S}$ are the linguistic input signals ("small" or " large") to node $(\mathrm{k}) \mathrm{x}_{\mathrm{k}}$ or $\left(\mathrm{Y}_{\mathrm{k}-2)}\right.$ and is the degree of (MF)for fuzzy group (X).

The form of the (MF) is trapezoidal or triangular and the components in this layer are known as the foundation parameters. Every node in the second layer is a fixed node identified by symbol $\Pi$. This layer's node output is a multiplication of all input signals [23], however:

Int J Pow Elec \& Dri Syst, Vol. 11, No. 2, June 2020 : $726-734$ 


$$
u_{2, k}=W_{k}=\mu_{x k}(x) * \mu_{Y k}(y) k=1,2
$$

The rule of fuzzy rules represented by the output of each node in this layer. The updating for the weights and changing process are not exit in this layer [3, 22].

Each node in the third layer each node is indicated by $(\mathrm{N})$ and considered as a fixed node. The node output $(\mathrm{k})$ is estimated through the provision of the rule $(\mathrm{k})$ for the summation of the provisions of the entire rules.

$$
u_{3, k}=\vec{w}_{k}=\frac{w i}{w 1+w 2} k=1,2
$$

The output of this layer are called "normalized firing strengths" In the fourth layer each node is adaptation node function:

$$
u_{4, k}=\vec{w} k f=\vec{w} k\left(e_{k} x+t_{k} y+k_{k}\right) \mathrm{k}=1,2
$$

Where $\vec{w} k$ is output of the third layer and $\left(\mathrm{k}_{\mathrm{k}}, \mathrm{t}_{\mathrm{k}}, \mathrm{e}_{\mathrm{k}}\right)$ are a group of elements of that node are called (consequent parameters).

Where is the third layer output and $\left(\mathrm{k}_{\mathrm{k}}, \mathrm{e}_{\mathrm{k}}, \mathrm{t}_{\mathrm{k}}\right)$ being resultant parameters of the node in this layer.

In the fifth layer each node (denoted by symbol $\Sigma$ ) is a fixed node. The terminal system output is the resultant output of this level. The contributions from each rule for the total incoming signals are the output of this layer:

$$
u_{5, k}=\frac{\mathrm{w} 1 \mathrm{f} 1+\mathrm{w} 2 \mathrm{f} 2}{\mathrm{w} 1+\mathrm{w} 2}
$$

\section{METHODOLOGY}

The IEEE 9-bus system is used to represent the proposed system using MATLAB /Simulink program. Figure 3 illustrates the system which comprises nine buses, three synchronous machines, six transmission lines, three transformers, three constant impedance loads and distance relays protecting for each transmission line [24].

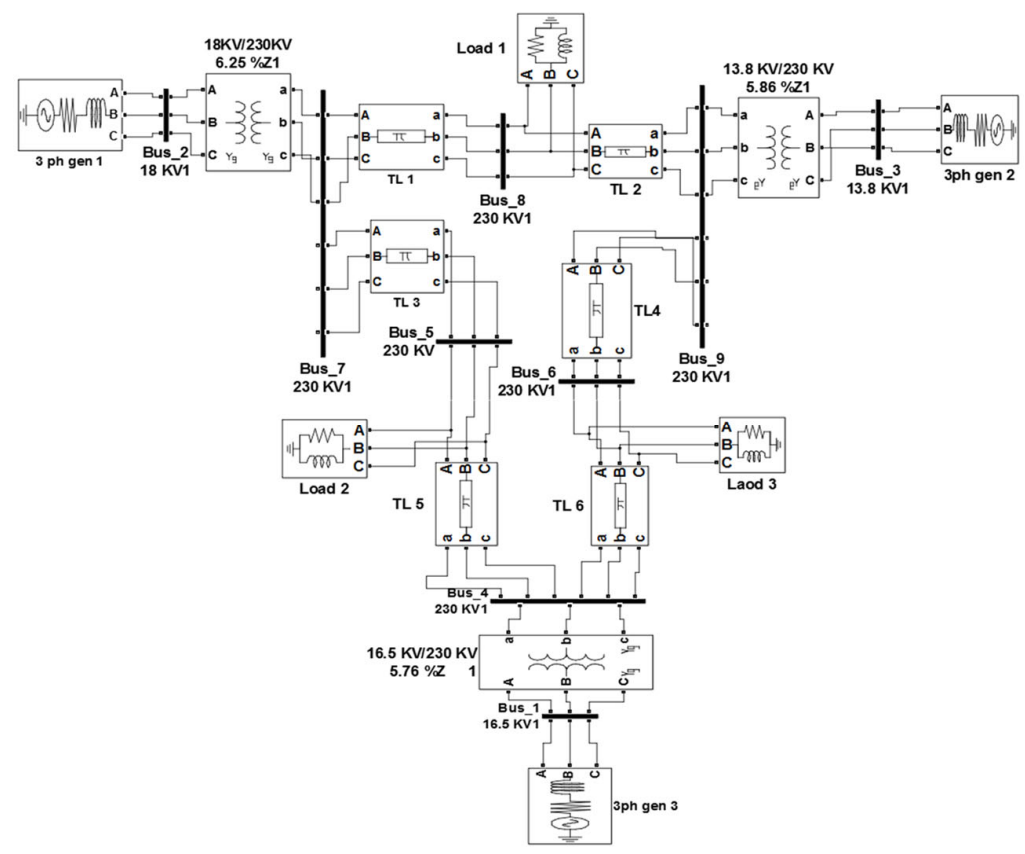

Figure 3. Depicts the Power System through the utilization of (Matlab/Simulink) 
The ANFIS approach has been used to detect the fault location and the isolated bus that exposed to the fault and to adapt other relays to not give a trip signal while the fault occurs out of the operating relay zone. The ANFIS approach learning are briefly presented by the steps as the follow:

Step 1: Make proper exercise data through critical contrast in the fault resistance just as loading and fault times are applied. This progression replicates ordinary examples for each kind of fault.

Step 2: Selection of a suitable ANFIS structure. In this step the development of different types of ANFIS modules to process different types of faults is achieved. For example, single-phase to ground faults comprise 4 data sources; and three-phase faults have 6 inputs. Data sources are the sizes of the major segments $(60 \mathrm{~Hz})$ of three-phase voltages and currents are estimated at the relay station.

Step 3: In this step through deal with analysis of the ANFIS structure is trained network adaptation on the basis of data off-line. Also, can choose the optimization method of FIS model parameters and the number of training epochs which leads to less errors value [25].

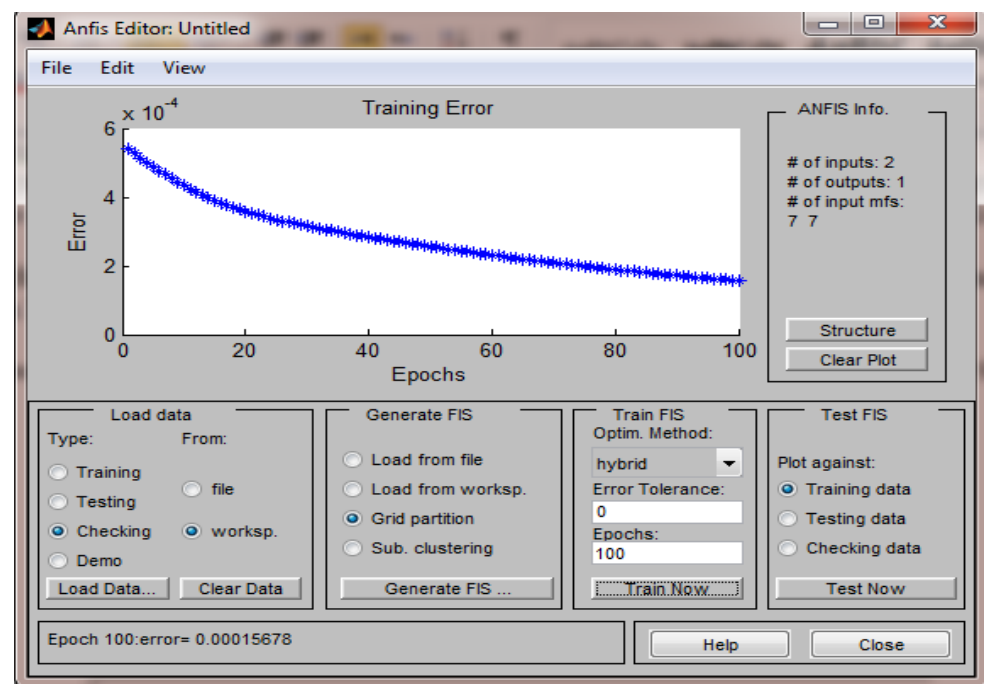

Figure 4. Depicts the training ANFIS for the distance relay

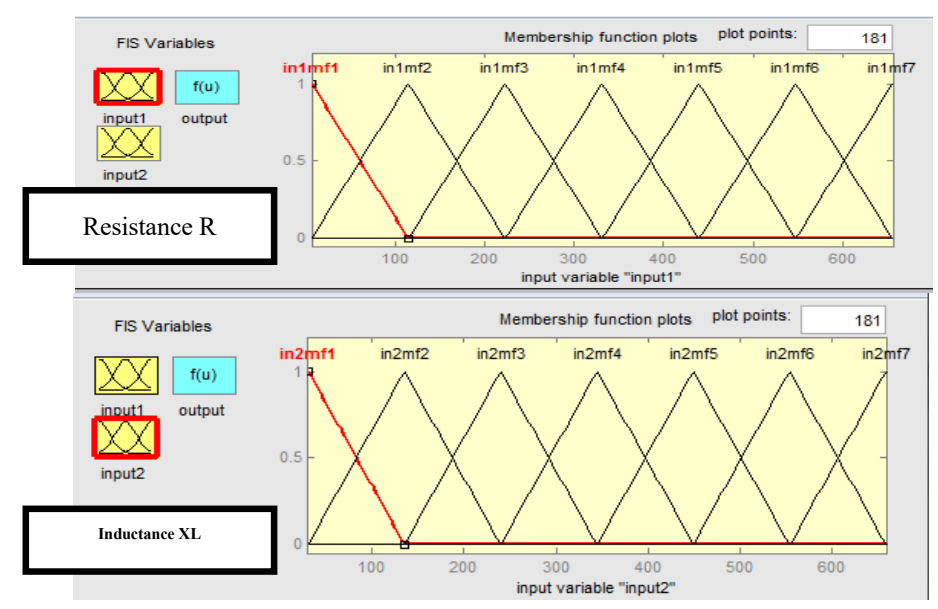

Figure 5. Depicts the MFS for anfis of distance relay for two input (R and X)

Step 4: In this progression prepared ANFIS is assessed by utilizing the test examples to get the best execution and to be attractive with the proposed ANFIS apparatus utilizing the MATLAB/Simulink tool kits. The ANFIS characteristics of the faults detection in the transmission lines 9-8 and line 4-5 are shown in Table 1.

Int J Pow Elec \& Dri Syst, Vol. 11, No. 2, June 2020 : 726 - 734 
Table-1: Shows ANFIS characteristics of the faults detection in the transmission lines 9-8 and line 4-5

\begin{tabular}{cc}
\hline Membership Function Type (MFT) & Triangle \\
\hline The number of entries & 2 (Resistance Reluctance of transmission line) \\
Number of input nodes & 14 \\
Number of rules nodes & 49 \\
Number of output nodes & 49 \\
Number of epoch training & 100 \\
\hline
\end{tabular}

Figure 6 fulfils the flowchart in the relay algorithm that can be found in three stages through the utilization of adaptable ANFIS and the identification of fault cases, and in ascertaining the value through other transitory cases. In addition, it ascertains the entire signal current and voltage (at a base of $60 \mathrm{~Hz}$ ) to process the rate of impedance and difference it and the setting. Figure 6 ANFIS based distance relay impedance. Moreover, ensuing that, will examine whether the blame is internal or external to the zone of protection. The six entries of the relay that the yield and voltages of the three stages illustrated possess a singular trip signal transmitted to the electrical switch.

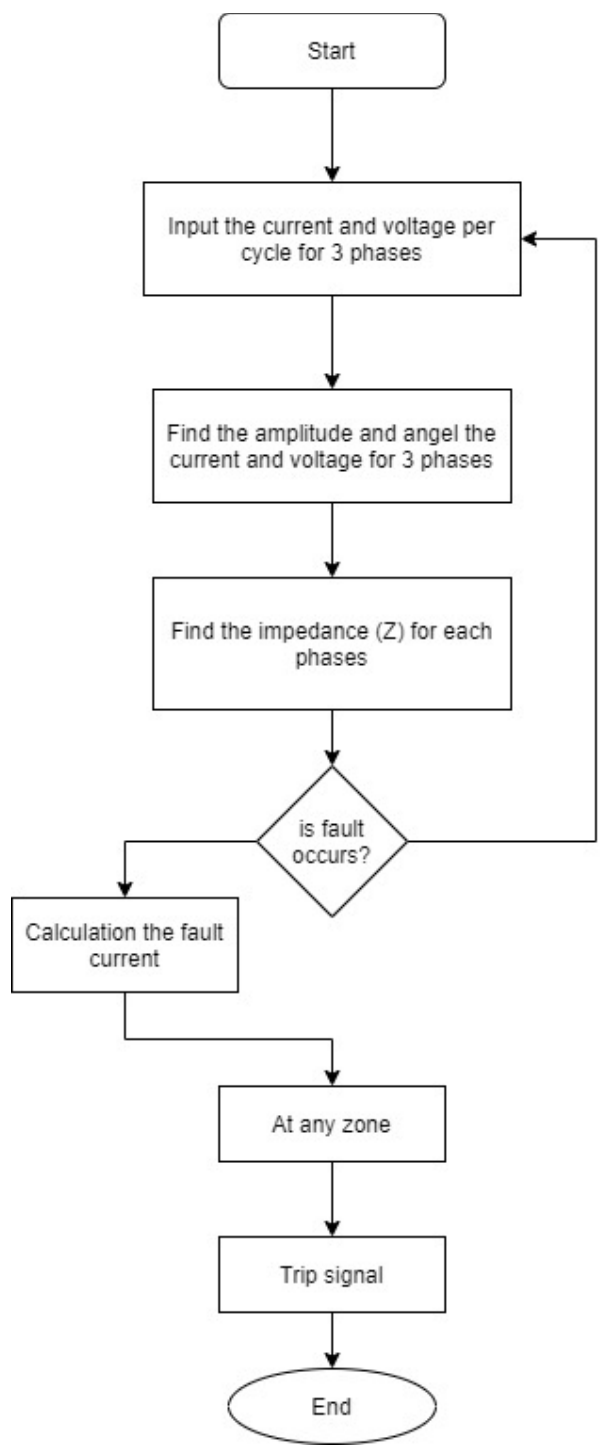

Figure 6. The flowchart in the relay algorithm 


\section{TEST RESULTS OF ANFIS DESIGNED RELAY ALGORITHM}

To guarantee the relay capacity to identify faults in the transmission line and determining the protection zone where the fault occurred, testing of the designed relay is achieved. Various fault cases on the transmission line across various locations are considered. The Table 3 presents the present values of the system when the fault occurred and after the occurrence on $50 \%$ of the transmission line at busbar 9-8, the type of fault is single-line (A) to ground. Table 4 shows the system current values before and after the fault occur at the $70 \%$ of the transmission line at bus bar $4-5$ and the type of the fault is three line $(\mathrm{ABC})$ to ground.

Table 3. Indicates the present system values prior to and ensuing the occurrences of faults

\begin{tabular}{|c|c|c|c|c|c|c|}
\hline \multirow[b]{2}{*}{$\begin{array}{l}\text { Number of the } \\
\text { line }\end{array}$} & \multicolumn{3}{|c|}{ The system current values before the fault } & \multicolumn{3}{|c|}{ The system current values after the fault } \\
\hline & $\begin{array}{c}\text { Peak current } \\
\text { Ia A }\end{array}$ & $\begin{array}{c}\text { Peak current } \\
\text { Ib A }\end{array}$ & $\begin{array}{c}\text { Peak current } \\
\text { Ic A }\end{array}$ & $\begin{array}{c}\text { Peak current } \\
\text { IaA }\end{array}$ & $\begin{array}{c}\text { Peak current } \\
\text { Ib A }\end{array}$ & $\begin{array}{c}\text { Peak current } \\
\text { Ic A }\end{array}$ \\
\hline $7-8$ & 193 & 193 & 193 & 282.5 & 290 & 299.6 \\
\hline $7-5$ & 145 & 145 & 145 & 92 & 82 & 96 \\
\hline $9-8$ & 131 & 131 & 131 & 1089 & 134.6 & 131 \\
\hline $9-6$ & 111.9 & 111.9 & 111.9 & 193.9 & 180.4 & 181.2 \\
\hline $4-6$ & 211 & 211 & 211 & 123 & 110.5 & 124.2 \\
\hline $4-5$ & 271.2 & 271.2 & 271.2 & 333 & 318 & 332 \\
\hline
\end{tabular}

Table 4. Shows the system current values before and after the faults occur

\begin{tabular}{|c|c|c|c|c|c|c|}
\hline \multirow[b]{2}{*}{$\begin{array}{l}\text { Number of the } \\
\text { line }\end{array}$} & \multicolumn{3}{|c|}{ The system current values before the fault } & \multicolumn{3}{|c|}{ The system current values after the fault } \\
\hline & $\begin{array}{c}\text { Peak current } \\
\text { Ia A }\end{array}$ & $\begin{array}{c}\text { Peak current } \\
\text { Ib A }\end{array}$ & $\begin{array}{c}\text { Peak current } \\
\text { Ic A }\end{array}$ & $\begin{array}{c}\text { Peak current } \\
\text { IaA }\end{array}$ & $\begin{array}{c}\text { Peak current } \\
\text { Ib A }\end{array}$ & $\begin{array}{c}\text { Peak current } \\
\text { Ic A }\end{array}$ \\
\hline $7-8$ & 193 & 193 & 193 & 94.2 & 80.7 & 99.2 \\
\hline $7-5$ & 145 & 145 & 145 & 323.9 & 339.6 & 303.7 \\
\hline $9-8$ & 131 & 131 & 131 & 268.7 & 263.4 & 262.1 \\
\hline $9-6$ & 111.9 & 111.9 & 111.9 & 82.7 & 106.1 & 82.8 \\
\hline $4-6$ & 211 & 211 & 211 & 316.2 & 289.7 & 309.1 \\
\hline $4-5$ & 271.7 & 271.7 & 271.7 & 1706 & 1785 & 1186 \\
\hline
\end{tabular}

It can also be observed that when the system is in its normal state, any fault occurs will affect the work of all the relays in the system. By applying the ANFIS approach the fault part only isolates without affecting the rest of the relays as shown in Table 5 and Table 6.

Table 5. Shows the relays characteristics under the faults in the transmission line 9-8

\begin{tabular}{cccc}
\hline No & $\begin{array}{c}\text { Distance } \\
\text { location }\end{array}$ & $\begin{array}{c}\text { State without } \\
\text { ANFIS }\end{array}$ & $\begin{array}{c}\text { State with } \\
\text { ANFIS }\end{array}$ \\
\hline 1 & $7-8$ & Trip & Non \\
2 & $9-8$ & Trip & Trip \\
3 & $7-5$ & Trip & Non \\
4 & $4-5$ & Trip & Non \\
5 & $4-6$ & Trip & Non \\
6 & $9-6$ & Trip & Non \\
\hline
\end{tabular}

Table 6. Shows the relays characteristics under the

\begin{tabular}{cccc} 
faults in the transmission line & 4-5 \\
\hline No & $\begin{array}{c}\text { Distance } \\
\text { location }\end{array}$ & $\begin{array}{c}\text { State without } \\
\text { ANFIS }\end{array}$ & $\begin{array}{c}\text { State with } \\
\text { ANFIS }\end{array}$ \\
\hline 1 & $7-8$ & Trip & Non \\
2 & $9-8$ & Trip & Non \\
3 & $7-5$ & Trip & Non \\
4 & $4-5$ & Trip & Trip \\
5 & $4-6$ & Trip & Non \\
6 & $9-6$ & Trip & Non \\
\hline
\end{tabular}

The ensuing representations indicate the varying voltage signals and the present system prior to and ensuing the faults incidents, at the instance of time (t-0.1 seconds).

a) The Indication of the Single-Phase Faults to the Ground (SL-G) Case.

b) The Indication of the Three-Phase Faults to the Ground (3 -Phase) Case.

Figure 7-8 Shows the voltage and current response for the Transmission line 9-8 with single line to ground fault and the voltage and current response for the Transmission line 4-5 with three phase fault to ground respectively. 


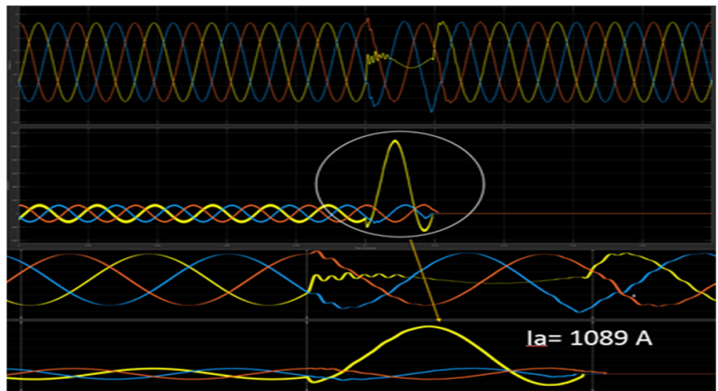

Figure 7. Voltage and current response for the Transmission line 9-8 with single line to ground fault

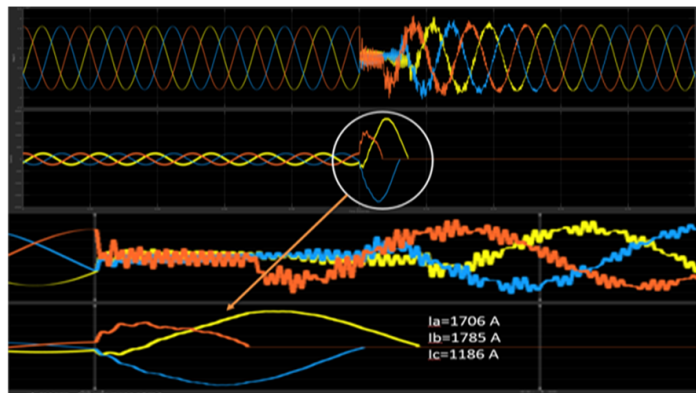

Figure 8. Voltage and current response for the Transmission line 4-5 with three phase fault to ground

\section{CONCLUSION}

Distance relay transfer structured by use of versatile neuro-fuzzy derivation system ANFIS was effective in distinguishing faults along the transmission line and in classifying fault types. Through the analyzed outcomes in this paper, the determined distance relay with supporting ANFIS algorithm for identification of fault occurrence and differentiate it from cases of disturbance a well as isolated fault location without affecting the work of other relays. The findings can aid one of the intelligent alternative techniques that have proved efficient in improving the transmission line.

\section{ACKNOWLEDGMENTS}

The authors are acknowledged Unviersity of Mosul for providing facilities to complete this work.

\section{REFERENCES}

[1] B. Taheri, et al., "Detection of power swing and fault occurring simultaneously with power swing using instantaneous frequency," Energy Syst., Jan 2019.

[2] Mohamed M. Ismail and M. A. Moustafa Hassan, "Distance relay protection for short and long transmission line," 5th International Conference on Modelling, Identification and Control (ICMIC), IEEE Conference, pp. 204 -211, Sept 2013

[3] J. R Kamel, T.S., Hassan, M.M. and El-Morshedy, A., "Using a combined artificial intelligent approach in distance relay for transmission line protection in EPS", Fifth International Conference on Soft Computing, Computing with Words and Perceptions in System Analysis, Decision and Control. IEEE Conference, Famagusta, Cyprus, pp.1-6, Sept. 2009

[4] R. Syahputra, "A Neuro - Fuzzy approach for the fault location estimation of unsynchronized two terminal transmission lines," International Journal of Computer Science \& Information Technology (IJCSIT), vol. 5, no 1, pp. 23 - 37, Feb 2010

[5] Babarinde, A.K., Adewuyi, P.A. and Adekunle, A., "Design of fuzzy logic-based relay for distance protection," FUOYE Journal of Engineering and Technology, vol.2, no. 2, 2017.

[6] S. A. Shaikh and at el., "Short circuit analysis \& over current relaying coordination of IEEE 9-Bus system," 2018 5th International Multi-Topic ICT Conference (IMTIC), Jamshoro, Pakistan, Apr 2018.

[7] Alsammak, A.N. and Abdulhameed, M.I.I., "Performance improvement for distance relay based fuzzy logic for all prospective facts," International Research Journal of Engineering and Technology (IRJET), vol. 5, no. 8, pp. 14891494, Aug 2018

[8] C. I. Ciontea, "The use of symmetrical components in electrical protection," 2019 72nd Conference for Protective Relay Engineers (CPRE), pp. 25-28, Mar 2019, College Station, TX, USA.

[9] P. Kundu, A. K. Pradhan, "Real-Time analysis of power system protection schemes using synchronized data", IEEE Transactions on Industrial Informatics, vol. 14, no. 9, Sept. 2018.

[10] Zadeh, H.K. and Li, Z., "A novel power swing blocking scheme using adaptive neuro-fuzzy inference system," Electric Power Systems Research, vol, 78, no. 7, pp. 1138-1146, 2008.

[11] Bonetti, A., Yalla, M.V. and Holst, S., "The IEC 60255-121: 2014 standard and its impact on performance specification, testing and evaluation of distance protection relays," In Transmission and Distribution Conference and Exposition, IEEE Conference, Dallas, TX, USA, pp. 1-6, May 2016.

[12] X. Lin, Y. Gao, P. Liu, "A novel scheme to identify symmetrical faults occurring during power," IEEE Trans. Power Del., vol. 23, no. 1, pp. 73-78, Jan. 2008.

[13] S. Lotfifard, J. Faiz, M. Kezunovic, "Detection of symmetrical faults by distance relays during power swings," IEEE Trans. Power Del., vol. 25, no. 1, pp. 81-87, Jan. 2010.

[14] E. P. Thwe and M. M. Oo, "Fault detection and classification for transmission line protection system using artificial 
neural network," Journal of Electrical and Electronic Engineering, vol.4, no. 5, pp. 89-96, 2016.

[15] S Hida and etal, "A critical review of distance relaying techniques under power swing condition," IEEE PES GTD Grand International Conference and Exposition Asia (GTD Asia), 2019.

[16] Abdullah, Amalina, "Fault identification using a new scheme of hybrid ANFIS," IEEE 15th Student Conference on Research and Development (SCOReD), Putrajaya, Malaysia, pp. 356 - 360, 2017.

[17] Yamen R. Al syoufi and Ammar A. Hajjar, "A high-speed algorithm to discriminate between power swing and faults in distance relays based on a fast wavelet," Electric Power Systems Research, Vol.172, pp 269-276.

[18] Huan, V.P., "An ANFIS based approach to improve the fault location on 110kV transmission line Dak Mil-Dak Nong," International Journal of Computer Science Issues (IJCSI),11(3), pp. 1, 2014.

[19] Saad AL-Kazzaz, Ibrahim Ismael, "On Line Tuning of PID Parameters using Fuzzy Logic for DC Motor Speed," International Journal of Scientific \& Engineering Research, vol. 7, no. 9, pp. 1518-1525, Sept. 2016.

[20] Ostamimonfared, A. Talebbaigy, T. Esmaeili, M. Fazeli and A. Kazemzadeh, "Cylindrical silicon nanowire transistor modeling based on adaptive neuro-fuzzy inference system (ANFIS)," J ElectrEng Technol (JEET), vol. 8, no. 5, pp. 1163-1168, 2013.

[21] R.A. Ghani, and at el., "Anfis approach for locating faults using gps coordinates in a distribution system", 7th Brunei International Conference on Engineering and Technology, pp. 4, 2018.

[22] Ibrahim Ismael, "The distance relay by using ANFIS to detect faults in transmission line," International Journal of Advancements in Research \& Technology, vol. 5, no. 9, pp. 14-21, 2016.

[23] Singh, G.K., and Al Kazzaz, Sa'ad Ahmed S., "Development of an Intelligent Diagnostic System for Induction Machine Health Monitoring," IEEE System Journal, vol. 2, no. 2, pp. 273-288, Jun 2008.

[24] Majid Sanaye-Pasand and Peyman Jafarian "An adaptive decision logic to enhance distance protection of transmission lines”, IEEE Transactions on Power Delivery, vol. 26, no. 4, pp. 2134-2144, 2011.

[25] Reddy, M. Jaya Bharata et al., "Smart fault location for smart grid operation using rtus and computational intelligence techniques," IEEE Systems Journal, vol. 8, no. 4, pp. 1260-1271, 2014.

\section{BIOGRAPHIES OF AUTHORS}
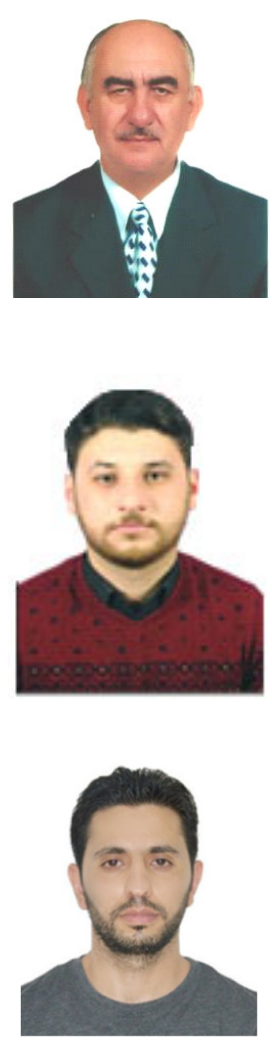

Sa'ad Ahmed S. Al Kazzaz was born in Mosul, Iraq, in 1960. He received the B.Sc. and the M.Sc. degree in electrical engineering from the University of Mosul, Mosul, Iraq in 1982 \& 1985 respectively, and Ph.D. degrees in electrical engineering from the Indian Institute of Technology (IIT) Roorkee, Roorkee, India, in 2001.

In Nov.1987, he joined Department of Electrical Engineering, University of Mosul as a lecturer. His current research interests include Intelligent Measurement and Monitoring of electrical equipment. He authored and coauthored about of 30 scientific papers publications in national and international journal.

Ibrahim Ismael abdulhameed: received the B.Sc. degree in electrical engineering from Mosul University, Mosul, Iraq, in 2011, and the M.Sc. degree in control system from the Mosul, Iraq, in 2014. His current research interests include classical control, Intelligent control and power system.

Karam Khairullah Mohammed: received the B.Sc. degree in electrical engineering from Mosul University, Mosul, Iraq, in 2012, and the M.Sc. degree in industrial power_control system from the Universiti Teknikal Malaysia Melaka (UTeM), Malaysia, in 2018. He is currently pursuing the $\mathrm{Ph} . \mathrm{D}$. degree with the Universiti Teknologi Malaysia (UTM), Malaysia. His current research interests include in industrial power control system. 